end of the procedure, $47(90.4 \%)$ had $\mathrm{mTICI} \geq 2 \mathrm{~b}$ and 35 $(67.3 \%)$ had $\mathrm{mTICI} \geq 2 \mathrm{c}$. No serious device-related adverse events were observed. Symptomatic intracranial hemorrhage developed in $1(1.92 \%)$ patient. Mean NIHSS score was 13 at 24 hours and 5 at discharge. At 90 days, 24 (46.2\%) patients were functionally independent (mRS 0-2).

Conclusions This preliminary study found good efficacy and safety for MIVI $\mathrm{Q}^{\mathrm{TM}}$ aspiration catheters used in combination with stent-retriever devices.

Table Shows main Angiographic, Clinical efficacy and safety outcomes.

Disclosures S. Remollo: None.

\section{E-128 COMPARISON OF EFFICACY AND OUTCOMES BETWEEN DIFFERENT THROMBECTOMY TECHNIQUES IN ACUTE BASILAR ARTERY OCCLUSION: A DUAL CENTER EXPERIENCE}

${ }^{1} \mathrm{~A}$ Monteiro* ${ }^{1} \mathrm{G}$ Cortez, ${ }^{1} \mathrm{M}$ Wagas, ${ }^{1} \mathrm{H}$ Rai, ${ }^{1} \mathrm{~A}$ Baig ${ }^{1} \mathrm{R}$ Dossani, ${ }^{1} \mathrm{C}$ Cappuzzo, ${ }^{1} \mathrm{~F}$ Almayman, ${ }^{2} \mathrm{~A}$ Aghaebrahim, ${ }^{1} \mathrm{~J}$ Davies, ${ }^{2} \mathrm{E}$ Sauvageau, ${ }^{1} \mathrm{~K}$ Snyder, ${ }^{2} \mathrm{R}$ Hanel, ${ }^{1} \mathrm{E}$ Levy, ${ }^{1}$ A Siddiqui. 'Neurosurgery, University at Buffalo Neurosurgery, Buffalo, NY; ${ }^{2}$ Cerebrovascular and Endovascular Surgery, Baptist Neurological Institute and Lyerly, Jacksonville, $F$

\subsection{6/neurintsurg-2021-SNIS.223}

Introduction Acute basilar artery occlusion $(\mathrm{aBAO})$ is a rare large vessel occlusion (LVO) associated with high morbidity and mortality. Modern thrombectomy devices are highly effective in achieving recanalization, but direct comparison of different techniques have not been performed in aBAO yet.

Methods Retrospective analysis of databases of LVO treated with endovascular intervention from 2 US endovascular neurosurgery centers. We included patients $\geq 18$-year-old with acute basilar artery occlusion treated with stent-retrievers or largebore aspiration catheters. The efficacy of Solumbra, Direct Aspiration First Pass (ADAPT) and stent-retriever alone (SR) techniques were compared, in addition to clinical outcomes.

Results Eighty-three patients were included. Median age was 67 years (IQR, 58-76) and 39.8\% were female. Median NIHSS at admission was 16 (IQR, 10-21). Intravenous alteplase was administered to 26 patients (31.3\%). Median time from onset-of-symptoms to puncture was 256 minutes (IQR, 157.5-363.0). Solumbra had significant higher rate of modified First Pass Effect (mFPE; $55 \%$ vs $31.8 \%, \mathbf{P}=0.032$ ), but not true First Pass Effect (FPE; 45\% vs 34.9\%, P=0.346). Good outcome (mRS 0-2) was not significantly different between the 3 techniques. Poor outcome (mRS 4-6) was associated with a higher median NIHSS (12.5 vs $19, \mathrm{P}=0.007)$, lower mean number of passes $(1.92$ vs $1.82, \mathrm{P}<0.001)$, higher rate of adjunctive therapy use $(10 \%$ vs $0 \%, \mathbf{P}<0.001)$ and higher rate of intraoperative complications $(10.7 \%$ vs $14.5 \%, \mathrm{P}=\mathbf{0 . 0 0 6})$. NIHSS at admission was found to significantly predict good outcome (OR 0.98, 95\%CI 0.97-.099, P=0.032). Incomplete recanalization after thrombectomy significantly predicted mortality (OR 1.68, 95\% CI 1.18-2.39; P=0.005).

Conclusion The evaluated techniques resulted in high recanalization rate. Solumbra is associated with higher rate of mFPE than ADAPT and SR, but clinical outcomes were similar. A lower NIHSS predicted patients with better prognosis, while incomplete recanalization after thrombectomy predicted mortality. Modern thrombectomy techniques are technically efficient in aBAO, but more studies are needed on prognostic factors of these patients.
Disclosures A. Monteiro: None. G. Cortez: None. M. Waqas: None. H. Rai: None. A. Baig: None. R. Dossani: None. J. Cappuzzo: None. F. Almayman: None. A. Aghaebrahim: None. J. Davies: 1; C; National Center for Advancing Translational Sciences of the National Institutes of Health under award number KL2TR001413 to the University at Buffalo. 2; C; Medtronic. 4; C; Cerebrotech, RIST Neurovascular. E. Sauvageau: None. K. Snyder: 2; C; Canon Medical Systems Corporation, Penumbra Inc., Medtronic, and Jacobs Institute. R. Hanel: None. E. Levy: 2; C; Claret Medical, GLG Consulting, Guidepoint Global, Imperative Care, Medtronic, Rebound, StimMed;. 4; C; NeXtGen Biologics, RAPID Medical, Claret Medical, Cognition Medical, Imperative Care (formerly the Stroke Project), Rebound Therapeutics, StimMed, Three Rivers Medical;. A. Siddiqui: 2; C; Amnis Therapeutics, Boston Scientific, Canon Medical Systems USA Inc., Cerebrotech Medical Systems Inc., Cerenovus, Corindus Inc., Endostream Medical Ltd., Imperative Care, Inc. Integra LifeSciences C. 4; C; Adona Medical, Inc, Amnis Therapeutics, (Purchased by Boston Scientific October 2017), Blink TBI Inc., Buffalo Technology Partners Inc., Cerebrotech Medical Systems, Inc., Cognition Medical, Endostrea.

\section{E-129 FLOW REDIRECTION ENDOLUMINAL DEVICE (FRED) FOR TREATMENT OF INTRACRANIAL ANEURYSMS: A SYSTEMATIC REVIEW}

${ }^{1} M$ Waqas*, ${ }^{1} R$ Dossani, ${ }^{2} M$ Alkhaldi, ${ }^{3} \mathrm{~J}$ Neveu, 'J Cappuzzo, 'J Liam, ${ }^{1} A$ Khan, ${ }^{3} \mathrm{~V}$ Lazarov, ${ }^{1} \mathrm{~A}$ Monteiro, ${ }^{1} \mathrm{I}$ Davies, ${ }^{1} \mathrm{~A}$ Siddiqui, ${ }^{1} \mathrm{E}$ Levy. ${ }^{1}$ Neurosurgery, University at Buffalo Neurosurgery, Buffalo, NY; ${ }^{2}$ Neurosurgery, Imam Abdulrhman Bin Faisal Univeristy, Dammam, Saudi Arabia; ${ }^{3}$ Neurosurgery, Jacobs School of Medicine and Biomedical Sciences, Buffalo, NY

\subsection{6/neurintsurg-2021-SNIS.224}

Introduction The Flow Redirection Endoluminal Device (FRED; MicroVention) is a dual-layered flow diverter used for the treatment of intracranial aneurysms. The objective of this systematic review was to compile device-related safety and effectiveness data.

Methods The literature from January 1, 2013 to June 30, 2020 was searched for studies describing use of the FRED for intracranial aneurysm treatment irrespective of aneurysm location and morphology. The review included anterior and posterior circulation ruptured and unruptured saccular, fusiform or dissection, and blister aneurysms. MeSH terms related to "flow re-direction endoluminal device" and "FRED for aneurysms" were used. Data related to indication, complications, and rates of aneurysm occlusion were retrieved and analyzed.

Results Twenty studies with 1674 intracranial aneurysms were included in this review. The overall reported morbidity was 0$20 \%$. Overall procedure-related mortality was $1.6 \%$ (range 0 $6 \%$ ). Complication rates fell into 5 categories: technical (3.8\%), ischemic (3.9\%), thrombotic orstenotic (5.9\%), hemorrhagic $(1.5 \%)$, and non-neurological $(0.8 \%)$. The aneurysm occlusion rate between 0 and 3 months (reported in 9 studies) was $47.8 \%$. The occlusion rate between 4 and 6 months (reported in 11 studies) was $73.1 \%$. Occlusion rates continued to increase to $75.1 \%$ at7-12 months (reported in 9 studies) and $87.0 \%$ for follow up beyond 1 year (reported in 8 studies).

Conclusion This review indicated that the FRED is a safe and effective for the treatment of intracranial aneurysms. Future studies should directly compare the FRED with other flow 